\title{
Aspek Hukum Positif Rahasia Dagang: Informasi pada Jasa Telekomunikasi di Indonesia
}

\author{
Tasya Safiranita, Sherly Ayuna Putri, Ahmad M Ramli, Mayesha \\ Andreana Yasmine
}

Faculty of Law, Universitas Padjadjaran

tasya_safiranita@yahoo.com

Submitted: 2020-08-19 ; Reviewed: 2020-10-02; Accepted: 2020-11-20

\begin{abstract}
Trade secrets which is a product of intellectual property Law, has a fairly high specificity relating to the activities of economic and business information, one of the relations with Data protection relating to a human right that needs to be protected by the state, one of which is on the law of telecommunications. The purpose of this research is to determine protection or positive law on telecommunication services in Indonesia and the extent of legal protection of Data information in Indonesia. The method of this research is juridical normative study, using secondary data with primary and secondary legal materials, then the data collection techniques applied were study of literature or documents, and qualitative juridical as technical analysis. The results of this research indicate that telecommunication's service in Indonesia have been regulated in the Law of The Republic of Indonesia Number 36 of 1999 regarding Telecommunications, but that Law has not disclose information as trade secrets in telecommunication service, as well as Law of The Republic Indonesia Number 19 of 2016 regarding Amendments to Law of the Republic of Indonesia Number 11 of 2008 regarding Electronic Information and Transactions which only help information but not as trade secrets, thus, Indonesia need to immediately ratify the Law of Personal Data Protection, so information such as customer data on telecommunications services as trade secrets can be protected.
\end{abstract}

Keywords: Trade secrets information; Data protection; Telecommunications. 


\section{PENDAHULUAN}

Kekayaan Intelektual adalah suatu sistem, ${ }^{1}$ yang sangat erat kaitannya dengan hukum benda, dikarenakan merupakan suatu hak eksklusif yang dapat diciptakan atas kreativitas manusia, hasil kreativitas tersebut merupakan suatu benda yang tidak berwujud yang bernilai tinggi secara ekonomi. ${ }^{2}$ Intellectual Property Rights merupakan kebendaan immaterial, ${ }^{3}$ pada Pasal 499 KUHPerdata menyebutkan bahwa "benda" yang dapat diklasifikasikan ke dalam berbagai kategori termasuk benda berwujud dan tidak berwujud. Justifikasi yang paling mendasar untuk HKI adalah dengan menekankan pada kejujuran dan keadilan. ${ }^{4}$

Dapat dikatakan bahwa proses berpikir yang dapat menghasilkan suatu karya, harus mendapatkan perlindungan hukum, karena sifat eksklusif yang terkandung dalam karya manusia merupakan suatu hak. ${ }^{5}$ oleh karenanya negara harus memberikan perlindungan hukum. Salah satu Kekayaan Intelektual yang berhubungan dengan suatu kontrak antara para pihak, yang timbul berdasarkan kejujuran adalah Rahasia Dagang. ${ }^{6}$ Kerahasiaan informasi sejatinya dilakukan guna melindungi hak dari pemilik suatu rahasia informasi tersebut agar tidak terbongkar dan diketahui oleh pihak lain. ${ }^{7}$ Adanya ekonomi digital, menunjukkan tingginya kepercayaan masyarakat yang penting ditumbuhkan dalam era digital dan informasi. ${ }^{8}$

Berdasarkan pengertian diatas, pelanggaran Rahasia Dagang terjadi apabila seseorang memperoleh atau menguasai Rahasia dagang tersebut dengan cara yang bertentangan dengan Undang-Undang yang berlaku, hal ini diatur dalam Pasal 14 Undang-Undang No. 30 Tahun 2000 tentang Rahasia Dagang, selain itu ada yang tidak dianggap pelanggaran Rahasia Dagang diatur dalam Pasal 15 Undang-Undang No. 30 tahun 2000 tentang Rahasia Dagang.

Mengingat bahwa informasi melalui jasa telekomunikasi hingga saat ini belum ada pengaturannya, maka jika dilihat dengan adanya perubahan pada era disrupsi saat ini yang membutuhkan hadirnya regulasi baru mengenai Rahasia Dagang sebagai sumber informasi penting perlu diatur dan dilindungi sedemikian komprehensif agar semakin menunjukan bahwa informasi tersebut adalah hal yang harus dijaga.

Dalam hal ini Indonesia memerlukan Undang-Undang Republik Indonesia yang secara implisit agar memberikan perlindungan hak Rahasia Dagang, diantaranya :

1. Dalam suatu konsep perdagangan secara global agar dapat bersaing perlu diciptakan suatu kreatifitas dari yang menghasilkan sebuah informasi atas

\footnotetext{
1 Achmad Zen Umar Purba., Hak Kekayaan Intelektual Pasca TRIPs, Bandung: Alumni, 2005, hlm. 1.

${ }^{2}$ H. OK. Saidin., Aspek Hukum Hak Kekayaan Intelektual, Jakarta: Raja Grafindo Persada, 2004, hlm. 9.

3 Rachmadi Usman., Hukum Hak Atas Kekayaan Intelektual, Bandung: Alumni, 2003, hlm. 1.

4 Tim Lindsey, dkk., Hak Kekayaan Intelektual Suatu Pengantar, Bandung: Alumni, 2004, hlm. 13.

5 Sujud Margono \& Amir Angkasa., Komerialisasi Aset Intelektual, Aspek Hukum Bisnis, Jakarta: Gramedia Widia Sarana Indonesia, 2002, hlm. 4.

${ }^{6}$ Ibid, hlm. 39.

${ }^{7}$ Fabiola, M, "Perlindungan Hukum Terhadap Rahasia Perusahaan Dalam Menghadapi Persaingan Bisnis Di Indonesia”, Lex Privatum, VII(4), 2019, hlm. 89.

${ }^{8}$ Zaheer \& Bachmann, Handbook of Trust Research, UK: Edward E. Limited, 2006, hlm. 235-236.
} 
rahasia dagang serta diperlukan perlindungan hukumnya sebagai salah satu produk dari KI.

2. berdasarkan Agreement Establishing the World Trade Organization serta Agreement of Trade Related (Persetujuan TRIPs) yang diratifikasi melalui UU No. 7 Tahun 1994, s[epimenjelaskan tujuan diundangkannya regulasi tentang Rahasia Dagang, yaitu :

a. Meningkatkan Industri di Indonesia;

b. mengembangkan invensi-invensi baru untuk meningkatkan industri terkait;

c. memberikan perlindungan hukum atas suatu invensi, diutamakan pada

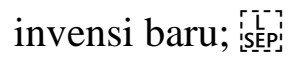

d. memberikan perlindungan hukum atas suatu invensi yang tidak melanggar atas hak pada rahasia dagang miliknya. ${ }^{9}$

Dalam dunia bisnis saat ini yang merupakan hasil perkembangan dari waktu ke waktu, pelindungan Rahasia Dagang adalah kebutuhan yang mutlak, karena ketidakpastian perihal Rahasia Dagang dapat menimbulkan persaingan tidak jujur (unfair competition), yang pada akhirnya akan mengganggu dunia bisnis secara menyeluruh. ${ }^{10}$

Terkait dengan para pihak dalam Rahasia Dagang, terlebih yang terikat pada suatu hubungan pekerjaan, dapat dimaknai bahwa pihak tersebut harus memiliki suatu kejelasan perihal waktu kepada pihak yang tidak terikat untuk agar terjaga atau dijaga kerahasiaan informasi. ${ }^{11}$

Berdasarkan penguraian latar belakang diatas maka penulis merumuskan permasalahan yang akan dibahas yaitu mengenai Bagaimanakah Perlindungan Hukum Positif Rahasia Dagang pada Jasa Telekomunikasi di Indonesia dan Sejauhmana Perlindungan Hukum atas Informasi Data di Indonesia.

\section{PEMBAHASAN}

\section{Hukum Positif pada Pengaturan Rahasia Dagang}

Indonesia belum memiliki pengaturan secara khusus mengenai Informasi pada Jasa Telekomunikasi, saat ini yang menjadi hal yang sangat berkaitan dengan Rahasia Dagang adalah sebuah informasi yang aksesnya terbatas hanya pada pemiliknya sehingga dianggap bersifat rahasia, Dalam kaitannya dengan Industri Jasa Telekomunikasi di Indonesia, telah diatur ketentuan terkait perlindungan yang

\footnotetext{
9 H. Adami Chazawi., Tindak Pidana Hak Atas Kekayaan Intelektual (HAKI), Malang: Bayu Media Publishing, 2007, hlm. 205-206.

10 Anastasia E. Gerungan, "Perlindungan Hukum Terhadap Rahasia Dagang Ditinjau Dari Aspek Hukum Perdata Dan Pidana Di Indonesia", Jurnal Hukum Unsrat Vol.22/No.5/Januari /2016, hlm.70.

${ }^{11}$ Ahmad M. Ramli., Perlindungan Rahasia Dagang dalam UU No. 30/2000 dan Perbandingan dengan beberapa Negara, Bandung: Mandar Maju, 2001, hlm. 73.
} 
menyangkut data pada UU ITE, UU Telekomunikasi dan PP Nomor 71 Tahun 2019 tentang Penyelenggaraan Sistem dan Transaksi Elektronik. Ketentuan ini membahas mengenai proteksi atas suatu data, pembongkaran data dan juga mengatur hal yang diperbolehkan dalam melakukan pembongkaran data pengguna jasa telekomunikasi, dimana hal ini mengikat secara umum atau khusus dan ditegakkan oleh pemerintah atau pengadian dalam Negara Indonesia. ${ }^{12}$

Sumber Hukum Positif dapat diartikan sebagai-bahan yang digunakan sebagai dasar oleh pengadilan dalam memutus perkara. ${ }^{13}$ Menurut Sudikno, kata sumber hukum sering digunakan dalam beberapa arti, ${ }^{14}$ sebagai asas hukum, sebagai sesuatu yang merupakan permulaan hukum, misalnya kehendak Tuhan, akal manusia jiwa bangsa dan sebagainya serta sumber berlakunya, yang memberi kekuatan berlaku secara formal kepada peraturan hukum (penguasa, masyarakat).

Rahasia Dagang dalam hukum perdata atas dasar perbuatan melawan hukum dapat mengakibatkan suatu perikatan terhadap pihak yang merugikan sehingga diperlukan untuk mengganti kerugian tersubut. Pasal 1365 BW menyebutkan bahwa:

"Perbuatan melawan hukum merupakan setiap perbuatan yang melanggar hukum yang membawa kerugian bagi orang lain, hal mana mewajibkan kepada pihak yang melakukan kesalahan itu memberi ganti kerugian kepada pihak yang dirugikan tersebut".

Berdasarkan hukum rahasia dagang, suatu pihak yang melanggar atas sebuah informasi pada suatu hak yang termasuk kedalam informasi yang dipunyai oleh pihak atau merupakan suatu nilai komersial maka disebut dengan perbuatan melawan hukum. Pasal 1365 BW memiliki tujuan agar substansi dari hukum perdata atas suatu pelanggaran yang dapat mendatangkan kerugian terhadap pihak lainnya. ${ }^{15}$

Suatu perjanjian yang dikatakan sebagai kekuatan hukum tetap atas rahasia dagang dapat dibuat dalam bentuk perjanjian merahasiakan (secrecy agreement). Suatu kontrak dapat ditujukan untuk memberikan perlindungan hukum tidak hanya untuk data secara utuh terdapat pada rahasia dagang termasuk kedalam technical experience)termasuk kedalam suatu proses, suatu pengolahan peralatan, bahan produk, dan suatu cara pengoperasian atas suatu mutu produk berdasarkan tingkat keamanan yang melindungi suatu informasi tentang formula yang merupakan suatu nilai komersial atas informasi tersebut. Rahasia Dagang merupakan bentuk hak atas kepemilikan kekayaan intelektual yang berbeda dari bentuk kekayaan intelektual (KI) lainnya. ${ }^{16}$ Adapun selain keuntungan ekonomi, keuntungan lain terhadap pemilik Rahasia Dagang adalah produk yang dihasilkan akan memiliki keunikan dan keunggulan di mata

12 I. Gede Pantja Astawa, Dinamika Hukum dan ilmu PerUndang-Undang Republik Indonesiaan di Indonesia, Bandung: Alumni, 2008, hlm. 56.

${ }^{13}$ Peter Mahmud Marzuku, Pengantar Ilmu Hukum, Jakarta: Kencana Prenada Media Group, hlm. 12.

14 Budi Ruhiatudin,Pengantar Ilmu Hukum, Yogyakarta: Teras, 2009, hlm. 29-30.

${ }^{15}$ Ahmad M. Ramli., Op Cit, hlm. 50.

16 Syafnul, D, "Perlindungan Rahasia Dagang dari Tindakan Persaingan Curang", Warta Universitas Dharmawangsa, 2018, hlm. 56, 1829. 
pelanggan. Pemegang Rahasia Dagang akan mampu menyediakan barang dan jasa yang lebih sesuai dari barang dan jasa milik pesaing dengan harga yang miring. Dengan begitu berbagai keuntungan dapat dengan mudah didapatkan. ${ }^{17}$ Aturan hukum yang mengatur upaya proteksi terhadap kerahasiaan informasi disebut sebagai hukum kerahasiaan informasi, atau dalam bahasa Inggris disebut Law of Confidence.

Rezim HKI ini adalah suatu hal yang dapat memberikan perlindungan atas suatu ide selain Paten. Terdapat suatu keuntungan atas perlindungan rhahasia dagang dibandingkan dengan paten yaitu suatu karya intelektual jika tidak memiliki syarat untu dipatenkan serta memiliki masa perlindungan hukum secara tidak terbatas serta proses perlindungannya tidak akan rumit dan perlu biaya tinggi layaknya paten, ini mrupakan suatu perlindungan secara geografis lebih banyak. Atas dasar suatu hak dan kewajiban atas suatu subjek termasuk kedalam suatu pengaturan bahwa suatu perusahaan pemberi informasi atas rahasia dagang dimana harus memiliki keterdediaan untuk memberikan informasi ysng diperlukan terhadap penerima, dengan garis besar bahwa suatu rahasia atas informasi tersebut tidak boleh diungkapkan pada pihak lain yang dapat digunakan untuk kepentingan lain diluar perjanjian. Suatu kewajiban ini memiliki keberlakuan terhadap suatu kontrak perjanjian selanjutnya yang memiliki kemungkinan untuk dilakukan oleh pihak penerima.

Rahasia dagang diberikan suatu perlindungan hukum jika suatu informasi bersifat rahasia yang diketahui oleh beberapa pihak saja, tidak secara keseluruhan masyarakat atau khalayak umum mengetahui hal tersebut. Suatu nilai ekonomi dapat dijadikan suatu proses bisnis secara komersial yang dapat menghasilkan revenue secara ekonomi maka dari itu perlu dijaga atas suatu rahasia antara para pihak tersebut, dalam suatu perjanjian. Definisi informasi merupakan aset yang memiliki nilai penting untuk diberikan perlindungan yang berkaitan erat dengan keamanannya. ${ }^{18}$ Tercerminnya sejumlah kegiatan yang secara ekstra dilakukan para pelaku usaha demi menjaga suatu informasi, jelas merefleksikan bahwa informasi rahasia dalam suatu kegiatan usaha merupakan hal yang esensial. Hal tersebut pun melabuhkan pada suatu pemikiran terkait alasan mengapa sebenarnya Rahasia Dagang memang perlu dilindungi secara hukum. ${ }^{19}$ Lisensi rahasia dagang dpat diproses dan dicatatkan ke Ditjen Kekayaan Intelektual. Pengecualian atau Batasan atas suatu kontrak memiliki beberapa kemungkinan apabila informasi yang digunakan atas dasar hal-hal berikut ini :

1. Seorang penerima sebelum menerima suatu perjanijian tidak dibolehkan baik secara langsung ataupun tidak berdasarkan dasar pengetahuan dari penerima dan pemberi;

\footnotetext{
17 Jeshfaghania, H. A., Gharibdoostyb, H. G., Shohreh, \& Lashkaryani, "Rights of Electronic Trade Secrets Holders, International Conference Research in Management Economics \& Accounting, 2018, hlm. 7.

${ }^{18}$ Mattord, W. M, Principles of Information security, 4th Edition, Kennesaw State University, Cengage Learning, 2011, hlm. 165.

${ }^{19}$ Lihat. http://lib.ui.ac.id/file?file=digital/2016-9/20269729-T37441-Irawaty.pdf Irawaty, Perkembangan dan Perspektif Yuridis Rahasia Dagang Sebagai Benda Jaminan Kredit. Universitas Indonesia.
} 
2. Apabila suatu waktu terjadi pengungkapan yang ditujukan pada penerima atau wakinya yang setelahnya tidak melakukan kelalaian atas dasar pihak penerima atau wakilnya dari suatu public information;

3. Apabila yang telah disediakan terhadap penerima dan pihak lain tanpa adanya Batasan atas suatu penggunaannya. ${ }^{20}$

\section{Informasi Perlindungan Data pada Jasa Telekomunikasi dan Pengaturannya di Indonesia}

Perlindungan Data adalah suatu Hak Asasi Manusia yang berlandaskan UUD 1945 negara Indonesia. Negara perlu menjamin perlindungan tersebut dalam bentuk aturan yang mengikat. Terlebih Indonesia adalah negara hukum, termasuk pada Pasal 1 ayat (3) UUD 1945, maka hukum dijadikan sebagai sarana untuk memberikan jaminan perlindungan atas hak tersebut. Data merupakan data pribadi jika data tersebut memiliki hubungan dengan suatu pihak yang dipakai sebagai cara memecahkan suatu permsalahan atau melakukan indentifikasi tersebut, yaitu yang dimaksud dengan pemilik data. ${ }^{21}$ Menilik pertumbuhan $e$-commerce yang potensial, membuat keberadaan regulasinya dinilai sangat esensial, ${ }^{22}$ dikarenakan rahasia dagang mulai berkembang melalui proses disrupsi.

Undang-Undang Republik Indonesia Nomor 36 Tahun 1999 tentang Telekomunikasi, ini berkaitan dengan data pribadi. Pasal 40 Undang- Undang Nomor 36 Tahun 1999 tentang Telekomunikasi mengatur tentang larangan kegiatan penyadapan. Setiap orang dilarang melakukan kegiatan penyadapan atas informasi yang disalurkan melalui jaringan telekomunikasi dalam bentuk apapun. Berdasarkan larangan pada pasal tersebut dapat dikatakan sebagai hal positif atas perlindungan data pribadi. Disebutkan juga pada Pasal 42 ayat (1) penyelenggara jasa telekomunikasi wajib merahasiakan informasi yang dikirim dan atau diterima oleh pelanggan jasa telekomunikasi melalui jaringan telekomunikasi dan atau jasa telekomunikasi yang diselenggarakannya.

Pasal 28 G ayat (1) UUD NRI 1945, meskipun tidak secara eksplisit menyebutkan privasi, juga telah mengamanatkan sekaligus mengakui bahwa hak atas privasi termasuk kedalam HAM tiap individu. Perlindungan data privasi juga merupakan bagian yang integral dari perlindungan privasi. Perlindungan data memiliki jangkauan yang luas berkenaan dengan perlindungan hukum atas suatu substansi pengaturan dengan memperhatikan beberapa unsur yang menjadi suatu persamaan atas suatu pengaturan

\footnotetext{
${ }^{20}$ Ibid, hlm. 54.

${ }^{21}$ European Union Agency for Fundamental Rights and Council of Europe, Handbook on European Data Protection Law, Belgium: Council of Europe, 2014, hlm. 36.

22 D. Pariadi, "Pengawasan Electronic Commerce ...," Jurnal Hukum dan Pembangunan, Vol. 48, Nomor 3,2018 , hlm.653
} 
hukum baik dalam data pribadi juga termasuk dalam perbandingan hukum diberbagai negara berkembang. ${ }^{23}$

Suatu hak atas perlindungan data dikembangkan agar dapat menjaga suatu kehormatan atas kehidupan pribadi dimana beberapa konsep yang dapat dijadikan acuan dalam berhubungan dengan suatu kehidupan masyarakat berdasarkan rekayasa sosial, dimana saat ini banyak hal yang berhubungan antara Penerapan Prinsip Perlindungan Data dengan Jasa Telekomunikasi. ${ }^{24}$

Suatu hak atas perlindungan data dikembangkan agar dapat menjaga suatu kehormatan atas kehidupan pribadi dimana beberapa konsep yang dapat dijadikan acuan dalam berhubungan dengan suatu kehidupan masyarakat berdasarkan rekayasa sosial, dimana saat ini banyak hal yang berhubungan antara Penerapan Prinsip Perlindungan Data dengan Jasa Telekomunikasi. ${ }^{25}$ Seiring dengan perkembangan disrupsi digital, perdagangan konvensional pun perlahan berubah dari yang bersifat offline ke online yang sangat bergantung pada jaringan internet. ${ }^{26}$ Lawrence Lessig, menyatakan bahwa internet adalah media yang dapat memenuhi kebutuhan untuk berinteraksi dan bertransaksi dalam cyberspace atau ruang maya. ${ }^{27}$

Perlindungan data privasi dalam UU ITE diakomodir hanya dalam satu pasal saja yakni pasal 26, yaitu:

“ 1. Kecuali ditentukan lain oleh peraturan perUndang-Undang Republik Indonesiaan, penggunaan setiap informasi melalui media elektronik yang menyangkut data pribadi seseorang harus dilakukan atas persetujuan orang yang bersangkutan.

2. Setiap orang yang dilanggar haknya sebagaimana dimaksud pada ayat (1) dapat mengajukan gugatan atas kerugian yang ditimbulkan berdasarkan Undang-Undang Republik Indonesia ini.

3. Setiap Penyelenggara Sistem Elektronik wajib menghapus Informasi Elektronik dan/atau Dokumen Elektronik yang tidak relevan yang berada di bawah kendalinya atas permintaan Orang yang bersangkutan berdasarkan penetapan pengadilan.

4. Setiap Penyelenggara Sistem Elektronik wajib menyediakan mekanisme penghapusan Informasi Elektronik dan/atau Dokumen Elektronik yang sudah tidak relevan sesuai dengan ketentuan peraturan perUndangUndang Republik Indonesiaan.

5. Ketentuan mengenai tata cara penghapusan Informasi Elektronik

\footnotetext{
23 Naskah Akademik, RancanganUndang-Undang Republik Indonesia Perlindungan Data Pribadi, Direktorat Jenderal Informasi Dan Komunikasi Publik, Kementerian Komunikasi dan Informatika Dan Cyber Law Center Fakultas Hukum, Universitas Padjadjaran, 2015, hlm. 116.

${ }^{24}$ European Union Agency for Fundamental Rights and Council of Europe, Supra No 5, hlm.37.

25 VerLoren van Themaat, W., \& Reuder, B. (2018). CHARTER OF FUNDAMENTAL RIGHTS OF THE EUROPEAN UNION. In European Competition Law. https://doi.org/10.4337/9781786435477.00032

26 Priyantono \& Mardi, “Digital Mastery: ...”, Jakarta: PT. Gramedia Pustaka Utama, 2017, hlm. 41.

${ }^{27}$ L. Lessig, Code Version 2.0, New York: Basic Books Publishing, 2006, hlm. 224
} 
dan/atau Dokumen Elektronik sebagaimana dimaksud pada ayat (2) dan ayat (4) diatur dalam peraturan pemerintah."

\section{PENUTUP}

Berdasarkan kepada pengaturan hukum positif tentang rahasia dagang yang disalahgunakan oleh pihak lain salah satu halnya adalah daftar pelanggan, proses penelitian, resep makanan suatu ide atau konsep serta sistem keuangan untuk menghasilkan atau mengubah hasil karya atas suatu produk yang dibuat berdasarkan bahan kimia atau mesin. Hukum kekayaan intelektual memberikan perlindungan atas suatu informasi atau konsep dalam wujud nyata sehingga suatu informasi tidak memiliki keharusan dalam suatu bentuk yang diuraikan dalam tulisan agar dapat dikatakan sebuah rahasia, maka dari itu produk kekayaan intelektual yang merupakan rahasia dagang memiliki perbedaan dengan rezim kekayaan intelektulal lainnya.

Bentuk perlindungan ini memungkinkan dilindunginya suatu kekayaan intelektual dalam jangka waktu yang tidak terbatas, pelindungan diberikan secara otomatis dan tidak ada biaya lain yang diperlukan untuk administrasinya kecuali dalam hal pendaftaran lisensi terkait.apabila ingin mendapat suatu perlindungan hukum beberapa syarat yang harus dipenuhi yaitu informasi yang bersifat rahasia, memiliki nilai komersial, memiliki upaya untuk dijaga kerahasiaannya melalui suatu kontrak antara para pihak yang dapat mengakses informasi yang merupakan rahasia dagang tersebut.

Regulasi selanjutnya yaitu Rancangan Undang-Undang Republik Indonesia Perlindungan Data Pribadi sebagai ius constituendum yaitu hukum yang dicita-citakan sebelumnya seharusnya menyesuaikan dengan negara maju lainnya sehingga dapat memberikan manfaat dalam bidang perekonomian namun tetap menerapkan konvergensi perlindungan hukum pada data pribadi pada Jasa Telekomunikasi. Indonesia perlu melakukan percepatan pengesahan atas perlindungan data sehingga dapat menempatkan Indonesia sejajar dengan negara yang memiliki tingkat ekonomi sangat maju, dimana negara-negara tersebut memiliki penerapan hukum secara global tentang perlindungan data dan tentu akan berkaitan dengan sistem yang mengacu pada ekonomi digital di masa revolusi industry 4.0 yang dapat menghasilkan suatu konvergensi perlindungan atas suatu bisnis yang saat ini bersandar pada jaringan internet berkenan dengan pengembangan Society 5.0

\section{DAFTAR PUSTAKA}

\section{Buku}

Achmad Zen Umar Purba., Hak Kekayaan Intelektual Pasca TRIPs, Bandung: Alumni, 2005.

Ahmad M. Ramli., HAKI: Teori Dasar Perlindungan Rahasia Dagang, Bandung: Mandar Maju, 2000. 
Ahmad M. Ramli., Perlindungan Rahasia Dagang dalam UU No. 30/2000 dan Perbandingan dengan beberapa Negara, Bandung: Mandar Maju, 2001.

Budi Ruhiatudin, Pengantar Ilmu Hukum, Yogyakarta, Teras, 2009.

H. Adami Chazawi., Tindak Pidana Hak Atas Kekayaan Intelektual (HAKI), Malang: Bayu Media Publishing, 2007.

H. OK. Saidin, Aspek Hukum Hak Kekayaan Intelektual, Jakarta: Raja Grafindo Persada, 2004.

Gede Pantja Astawa, Dinamika Hukum dan ilmu Perundang-Undangan Republik Indonesiaan di Indonesia, Bandung: Alumni, 2008.

Jeshfaghania, H. A., Gharibdoostyb, H. G., Shohreh, \& Lashkaryani, N. Rights of Electronic Trade Secrets Holders. International Conference Research in Management Economics \& Accounting, 7. 2018.

L. Lessig, Code Version 2.0, New York: Basic Books Publishing, 2006.

Mattord, W. M., Principles of Information security, 4th Edition. Kennesaw State University, Cengage Learning, 2011.

Peter Mahmud Marzuku, Pengantar Ilmu Hukum, Jakarta: Kencana Prenada Media Group, 2011.

Priyantono \& Mardi, "Digital Mastery: ...”, Jakarta: PT. Gramedia Pustaka Utama, 2017.

Rachmadi Usman., Hukum Hak Atas Kekayaan Intelektual, Bandung: Alumni, 2003.

Syafnul, D. Perlindungan Rahasia Dagang dari Tindakan Persaingan Curang, Medan: Warta Universitas Dharmawangsa, 2018.

Sujud Margono \& Amir Angkasa., Komerialisasi Aset Intelektual, Aspek Hukum Bisnis, Jakarta: Gramedia Widia Sarana Indonesia, 2002.

Zaheer \& Bachmann, "Handbook of Trust Research", UK: Penerbit Edward E. Limited, 2006.

\section{Peraturan Perundang-undangan}

Undang-Undang Republik Indonesia Dasar Republik Indonesia Tahun 1945.

Undang-Undang Republik Indonesia Nomor 36 Tahun 1999 Tentang Telekomunikasi.

Undang-Undang Republik Indonesia Nomor 19 Tahun 2016 tentang Perubahan atas Undang-Undang Republik Indonesia Nomor 11 Tahun 2008 tentang Informasi dan Transaksi Elektronik.

\section{Jurnal}

Anastasia E. Gerungan, "Perlindungan Hukum Terhadap Rahasia Dagang Ditinjau Dari Aspek Hukum Perdata Dan Pidana Di Indonesia", Jurnal Hukum Unsrat Vol.22/No.5/Januari $/ 2016$.

Fabiola, M. "Perlindungan Hukum Terhadap Rahasia Perusahaan Dalam Menghadapi Persaingan Bisnis Di Indonesia”. Lex Privatum, VII(4), 89, 2019. 
Dialogia luridica: Jurnal Hukum Bisnis dan Investasi

Volume 2 Nomor 1, November 2020

VerLoren van Themaat, W., \& Reuder, B. . "CHARTER OF FUNDAMENTAL RIGHTS OF THE EUROPEAN UNION. In European Competition Law”. 2018. https://doi.org/10.4337/9781786435477.00032

\section{Lain-lain}

European Union Agency for Fundamental Rights and Council of Europe, Handbook on European Data Protection Law, Belgium, 2014.

Naskah Akademik, RancanganUndang-Undang Republik Indonesia Perlindungan Data Pribadi, 2015, Direktorat Jenderal Informasi Dan Komunikasi Publik, Kementerian Komunikasi dan Informatika Dan Cyber Law Center Fakultas Hukum, Universitas Padjadjaran. 